\title{
Outcomes and complications of different surgical treatments for idiopathic normal pressure hydrocephalus: a systematic review and meta-analysis
}

\author{
Enrico Giordan, MD, ${ }^{1}$ Giorgio Palandri, MD, ${ }^{2}$ Giuseppe Lanzino, MD, ${ }^{1}$ \\ Mohammad Hassan Murad, MD, ${ }^{3}$ and Benjamin D. Elder, MD, PhD ${ }^{1}$ \\ 'Department of Neurologic Surgery and ${ }^{3}$ Evidence-Based Practice Center, Mayo Clinic, Rochester, Minnesota; and ${ }^{2}$ RCCS \\ Institute of Neurological Sciences of Bologna, Division of Neurosurgery, Bellaria Hospital, Bologna, Italy
}

\begin{abstract}
OBJECTIVE Different CSF diversion procedures (ventriculoperitoneal, ventriculoatrial, and lumboperitoneal shunting) have been utilized for the treatment of idiopathic normal pressure hydrocephalus. More recently, endoscopic third ventriculostomy has been suggested as a reasonable alternative in some studies. The purpose of this study was to perform a systematic review and meta-analysis to assess overall rates of favorable outcomes and adverse events for each of these treatments. An additional objective was to determine the outcomes and complication rates in relation to the type of valve utilized (fixed vs programmable).
\end{abstract}

METHODS Multiple databases (PubMed, Ovid MEDLINE In-Process \& Other Non-Indexed Citations, Ovid MEDLINE, Ovid Embase, Ovid Cochrane Central Register of Controlled Trials, Ovid Cochrane Database of Systematic Reviews, and Scopus) were searched for studies involving patients with idiopathic ventriculomegaly, no secondary cause of hydrocephalus, opening pressure $<25 \mathrm{~mm} \mathrm{Hg}$ on high-volume tap or drainage trial, and age $>60$ years. Outcomes included the proportion of patients who showed improvement in gait, cognition, and bladder function. Adverse events considered in the analysis included postoperative ischemic/hemorrhagic complications, subdural fluid collections, seizures, need for revision surgery, and infection.

RESULTS A total of 33 studies, encompassing 2461 patients, were identified. More than $75 \%$ of patients experienced improvement after shunting, without significant differences among the different techniques utilized. Overall, gait improvement was observed in $75 \%$ of patients, cognitive function improvement in more than $60 \%$, and improvement of incontinence in $55 \%$. Adjustable valves were associated with a reduction in revisions ( $12 \%$ vs $32 \%)$ and subdural collections ( $9 \%$ vs $22 \%$ ) as compared to fixed valves.

CONCLUSIONS Outcomes did not differ significantly among different CSF diversion techniques, and overall improvement was reported in more than $75 \%$ of patients. The use of programmable valves decreased the incidence of revision surgery and of subdural collections after surgery, potentially justifying the higher initial cost associated with these valves. https://thejns.org/doi/abs/10.3171/2018.5.JNS1875

KEYWORDS idiopathic normal pressure hydrocephalus; iNPH outcomes; third ventriculostomy; iNPH adverse events; hydrocephalus systematic review; iNPH complications

$\mathrm{D}$ IFFERENT strategies have been proposed for the treatment of idiopathic normal pressure hydrocephalus (iNPH). Ventriculoperitoneal (VP) or, less commonly, ventriculoatrial (VA) and lumboperitoneal (LP) shunting are the preferred methods for diverting cerebrospinal fluid (CSF). In the past 20 years, endoscopic third ventriculostomy (ETV) has also been suggested as a reasonable alternative, though this is typically recommended when there is evidence of aqueductal stenosis or fourth ventricle outflow obstruction.

There are no randomized studies comparing the efficacy of the various techniques, and it is difficult to identify the merits of one method over the other. The objective of this study was to perform a systematic review and meta-

ABBREVIATIONS CSF = cerebrospinal fluid; ETV = endoscopic third ventriculostomy; iNPH = idiopathic normal pressure hydrocephalus; iNPHGS = iNPH grading scale; $\mathrm{LP}=$ lumboperitoneal; $\mathrm{mRS}=$ modified Rankin Scale; $\mathrm{VA}=$ ventriculoatrial; $\mathrm{VP}=$ ventriculoperitoneal.

SUBMITTED January 10, 2018. ACCEPTED May 23, 2018.

INCLUDE WHEN CITING Published online November 23, 2018; DOI: 10.3171/2018.5.JNS1875. 
2010 records identified through database searching or additional sources

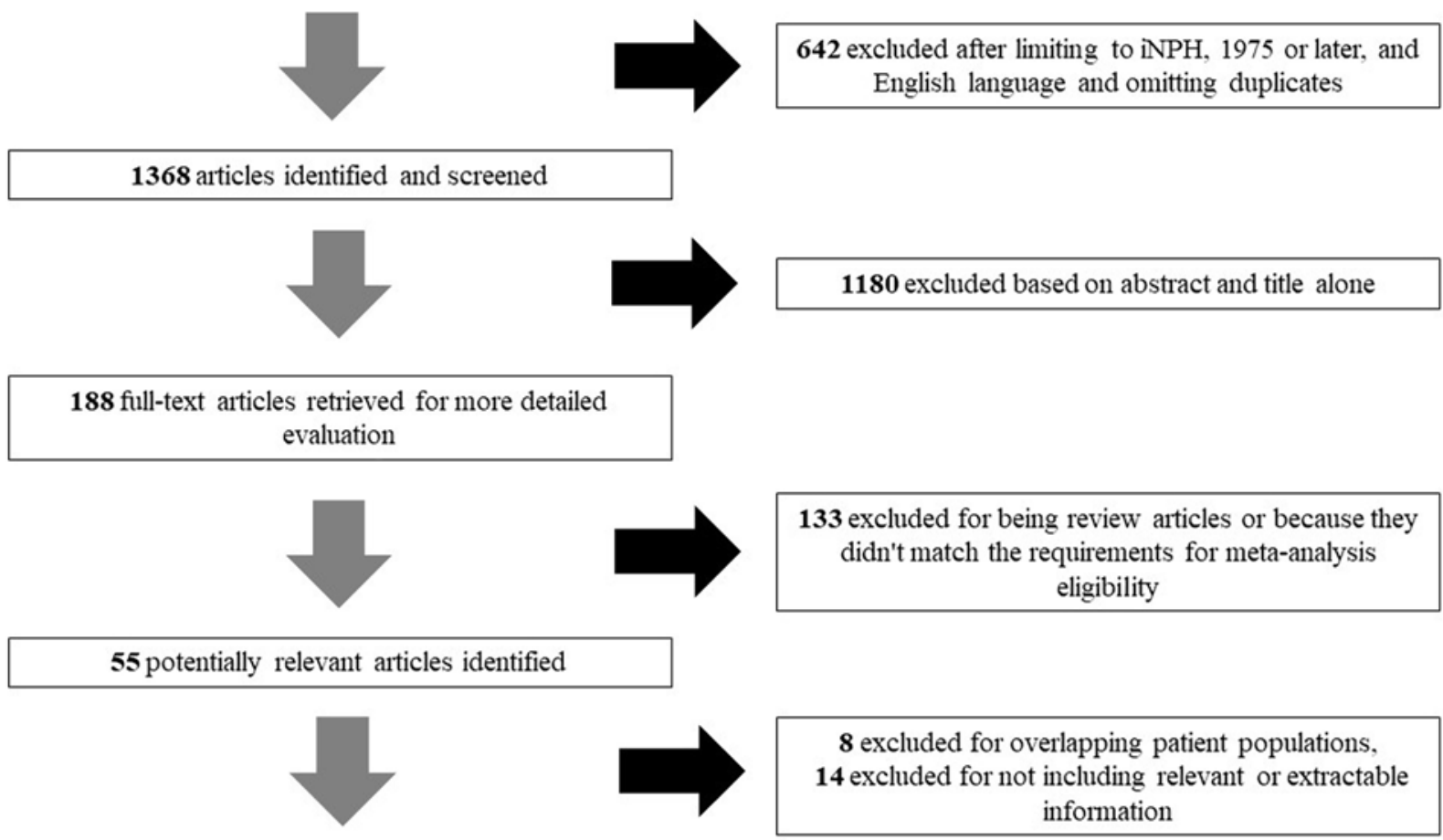

33 studies provided data for meta-analysis

FIG. 1. Flow diagram summarizing the process of study selection.

analysis to estimate the overall rate of favorable outcomes and adverse events for each of the more common treatment modalities utilized in the treatment of iNPH.

\section{Methods}

This systematic review is reported in accordance with the Preferred Reporting Items for Systematic Reviews and Meta-Analyses (PRISMA, 2009) statement (Fig. 1). ${ }^{27}$

\section{Literature Search, Study Selection, and Eligibility Criteria}

A medical reference librarian developed and executed a comprehensive literature search of PubMed, Ovid MEDLINE In-Process \& Other Non-Indexed Citations, Ovid MEDLINE, Ovid Embase, Ovid Cochrane Central Register of Controlled Trials, Ovid Cochrane Database of Systematic Reviews, and Scopus from 1975 to November 2017 to encompass more modern treatments of iNPH. The search was limited to manuscripts in the English language.

The following search terms were used: "hydrocephalus", "normal pressure hydrocephalus", "iNPH", "iNPH treatment", "surgery for hydrocephalus". The search identified 2010 citations. The question posed in this systematic review was: What are the rates of improved outcomes and of major adverse events after iNPH treatment?

At first, only titles were examined, and the nonrelevant articles were excluded. Subsequently, abstracts were re- viewed, and the full text of any study of interest was obtained. The full text of each selected study was thoroughly reviewed by one of the investigators (E.G.), and only studies concerning exclusively patients with iNPH and with an adequate description of the diagnostic criteria, treatment, and outcome were included in the meta-analysis. The reference lists of these studies were cross-examined, and additional studies were added as indicated. Case reports, editorials, meta-analyses, review articles, and duplicative reports were excluded along with any series including less than 25 patients or with clinical or imaging follow-up of less than 3 months. There was a paucity of studies on ETV that matched the inclusion criteria, so these were not included in the statistical comparisons of different shunt treatments, but the outcomes are presented separately for the sake of completeness. Studies with mixed populations of patients treated with different methods were excluded if it was not possible to clearly distinguish outcomes and complications related to each of the different treatment methods. To be included in the analysis, studies must have fulfilled the criteria presented below, covering 2 main domains: 1) patient selection and definition of iNPH; and 2) outcome assessment after surgical treatment.

The inclusion criteria were as follows:

1. Patient selection and definition of iNPH

a. Idiopathic ventriculomegaly (Evans index $>0.3$ 
on CT or MRI), no secondary cause of hydrocephalus (e.g., no positive history of tumor, infections, and neurodegenerative diseases) on imaging, and no obstructive cause (i.e., no aqueduct stenosis or fourth ventricle outflow obstruction)

b. Opening pressure $<25 \mathrm{~mm} \mathrm{Hg}$ on high-volume tap or drainage trial

c. Improvement of clinical symptoms, with gait given primary importance

d. Patients aged $>60$ years, or if no patient-level data provided, mean/median age $>70$ (lower limit of $95 \% \mathrm{CI}>50$ years)

2. Outcome assessment after surgical treatment: Positive outcome was defined as overall improvement and differentiated into the 3 clinical domains (gait, urinary incontinence, and cognition).

Positive overall outcome included any of the following:

- > 1-point improvement at any evaluation point for iNPHGS ${ }^{25}$ (idiopathic normal pressure hydrocephalus grading scale) or JCSRIH $^{36}$ (Japanese Committee for Scientific Research on Intractable Hydrocephalus) grading system

- > 1-point improvement on the modified Rankin Scale (mRS)

- >1-point in the Kiefer score

- "Fair" to "excellent" on the Black ${ }^{46}$ (or Marmarou" scale

- > 10-point improvement on the EQ-VAS (Euro-QoL visual analog scale)

For gait, positive outcome was defined as any of following:

- >1-point improvement in the gait section of iNPHGS

- $>10 \%$ improvement on the Timed-Up-andGo test

- $>20 \%$ reduction in gait time

- Measurable improvement on an administered motor score (e.g., $>5 \%$ on EquiTest CDP [computerized dynamic posturography])

For cognition, a positive outcome included any of following:

- > 1-point improvement in the cognitive section of iNPHGS

- > 2-point improvement on the MMSE (Mini-Mental State Examination)

- Improvement in verbal IQ, performance IQ, or full-scale IQ on the WAIS-R (Wechsler Adult Intelligence Scale-Revised) or WAIS-III (WAIS-Third Edition)

- > 5-point improvement on the ACE-R (Addenbrooke's Cognitive Examination-Revised)

For urinary incontinence, a positive outcome was characterized by any of the following:

- > 1-point improvement on the urinary section of iNPHGS
- Reduction of episodes of incontinence or improvement of bladder control

Studies that fulfilled the inclusion criteria, reporting any outcome in at least one or more of the 3 clinical areas (i.e., gait, urinary incontinence, or cognition) and/ or describing adverse events rates, were included in the analysis. Based on these inclusion and exclusion criteria, a total of 33 articles were identified. For each study, the proportion of patients who improved or experienced an adverse event was measured. Due to the heterogeneity in definitions of clinical improvement used in the identified literature, and because there is not yet a universally agreed-upon standardized grading system, any objectively measured outcome was used to identify improvement in this meta-analysis. In Table 1, a description of the grading scores utilized for each case series is presented. Adverse event rates were calculated by considering the occurrences of postoperative ischemic events, intraparenchymal hematoma, any subdural fluid collections (chronic or acute hematomas or hygromas), seizures, need for revision, and infections.

\section{Evaluation of Methodological Quality}

For each study, the risk of bias was assessed through the modified Newcastle-Ottawa quality assessment scale. Bias was defined based on the following questions: Did the study include all patients or consecutive patients with adequate clinical follow-up (at least 3 years)? Was outcome assessment objective and replicable? Did the assessment score scale consider all 3 dimensions of gait, dementia, and urinary dysfunction?

Studies judged to have a low risk of bias were defined as those with a predefined study protocol (prospective or randomized), adequate clinical follow-up ( $\geq 3$ years), objective and replicable assessment scales (iNPH score, mRS score, Kiefer score, Stein and Langfitt scale, Black rating scale), and CT or MRI at follow-up. Risk-of-bias results are summarized in Table 2.

\section{Statistical Analysis}

For each cohort, the proportion of patients considered improved and the proportion of patients with adverse events were estimated. The rates of the events were pooled in a meta-analysis across studies by using the DerSimonian and Laird random-effect models. ${ }^{6}$ Anticipating heterogeneity between studies, this model was chosen a priori because it incorporated both within- and between-studies variance. Also, because the rate of outcomes was close to 0 or 1 in some studies, the Freeman-Tukey double arcsine transformation was utilized. All statistical analyses were performed using Stata version 13.0 (StataCorp).

\section{Results \\ Search Results}

Thirty-three studies, encompassing 2461 patients, were identified. Eleven studies were retrospective and 22 were prospective. VP shunting was the exclusive treatment modality in 20 studies (1412 patients), VA shunting in 2 (108 patients), LP shunting in 4 (209 patients), and ETV 
TABLE 1. Summary of the characteristics of the included studies

\begin{tabular}{|c|c|c|c|}
\hline Authors \& Year & Diagnostic Criteria for iNPH & Treatment & Study Design \\
\hline Tullberg et al., 2018 & 1) ventriculomegaly on $\mathrm{CT}$ or $\mathrm{MRl} ; 2$ ) $\geq 1$ of triad $\mathrm{Sx}$; 3 ) no secondary cause & VP shunt & Prospective \\
\hline Hung et al., 2017 & 1) ventriculomegaly on $\mathrm{CT}$ or $\mathrm{MRI} ; 2$ ) $\geq 1$ of triad $\mathrm{Sx}$; 3) no secondary cause & VP/VA shunt & Retrospective \\
\hline Kanno et al., 2017 & $\begin{array}{l}\text { 1) age }>60 \text { yrs; 2) } \geq 1 \text { of triad } \mathrm{Sx} \text {; 3) Evans index }>0.3 \text { on } \mathrm{CT} \text { or MRI; 4) } \mathrm{CSF}<20 \mathrm{~cm} \mathrm{H}_{2} \mathrm{O} \text { or } \\
\text { pos CSF tap test; 5) normal CSF content; } 6 \text { ) no secondary cause }\end{array}$ & VP shunt & Prospective \\
\hline Thompson et al., 2017 & 1) age > 80 yrs; 2) preop timed walk test; 3) preop neuropsych tests; 4) Dx of possible iNPH & VP shunt & Retrospective \\
\hline Craven et al., 2016 & 1) ventriculomegaly on MRI or CT; 2) age > $40 \mathrm{yrs}$; 3) $\geq 1$ of triad $\mathrm{Sx}$; 4) no secondary cause & VP shunt & Prospective \\
\hline Liu et al., 2016 & 1) $>21 \mathrm{yrs} ; 2$ ) $\geq 1$ of triad $S x$; 3) no secondary cause; 4) Evans index $>0.3$ on CT or MRI & VA shunt & Retrospective \\
\hline Illán-Gala et al., 2015 & 1) no secondary cause; 2) $\mathrm{CSF}<20 \mathrm{~cm} \mathrm{H}_{2} \mathrm{O}$ or pos CSF tap test; 3) Dx of probable iNPH & VP shunt & Prospective \\
\hline Shaw et al., 2016 & 1) $\geq 1$ of triad $\mathrm{Sx}$; 2) Evans index $>0.3$ on $\mathrm{CT}$ or MRI; 3) CSF $<20 \mathrm{~cm} \mathrm{H}_{2} \mathrm{O}$ or pos CSF tap test & VP shunt & Prospective \\
\hline Suchorska et al., 2015 & $\begin{array}{l}\text { 1) } \geq 1 \text { of triad } \mathrm{Sx} \text {; 2) Evans index }>0.3 \text { on CT or MRI; 3) CSF }<20 \mathrm{~cm} \mathrm{H}_{2} \mathrm{O} \text { or pos CSF tap test; } \\
\text { 4) no secondary cause }\end{array}$ & VP shunt & Prospective \\
\hline Kazui et al., 2015 & $\begin{array}{l}\text { 1) age }>60 \text { yrs; 2) } \geq 1 \text { of triad Sx; 3) Evans index }>0.3 \text { on CT or MRI; 4) no secondary cause; } \\
\text { 5) normal CSF content }\end{array}$ & LP shunt & ctive \\
\hline Moriya et al., 2015 & $\begin{array}{l}\text { 1) age }>60 \text { yrs; 2) triad Sx; 3) Evans index }>0.3 \text { on CT or MRI; 4) no secondary cause; 5) } \\
\text { normal CSF content }\end{array}$ & LP shunt & tive \\
\hline Sankey et al., 2015 & 1) $\geq 1$ of triad $S x$; 2) Evans index $>0.3$ on $\mathrm{CT}$ or MRI; 3) no secondary cause & VP shunt & Retrospective \\
\hline Petersen et al., 2014 & 1) age $>21 \mathrm{yrs} ; 2$ ) $\geq 1$ of triad $\mathrm{Sx}$; 3) Evans index $>0.3$ on $\mathrm{CT}$ or MRl; 4) no secondary cause & VP shunt & Prospective \\
\hline Nakajima et al., 2015 & 1) $\geq 1$ of triad $\mathrm{Sx}$; 2) Evans index $>0.3$ on $\mathrm{CT}$ or MRI; 3) no secondary cause & LP shunt & Retrospective \\
\hline Virhammar et al., 2014 & 1) ventriculomegaly on MRI or $\mathrm{CT}$; 2) $\geq 1$ of triad $\mathrm{Sx}$; 3) no secondary cause & VP shunt & Prospective \\
\hline Eshra, 2014 & 1) $\mathrm{MRI}$; 2) 2 or more of triad Sx; 3) Evans index $>0.30$; 4) no secondary cause & ETV & Prospective \\
\hline Koivisto et al., 2013 & 1) $\geq 1$ of triad $S x ; 2$ ) no secondary cause; 3) Evans index $>0.3$ on $C T$ or MRI & VP shunt & Retrospective \\
\hline Freimann et al., 2013 & $\begin{array}{l}\text { 1) } \geq 1 \text { of triad } \mathrm{Sx} \text {; 2) Evans index }>0.3 \text { on CT or MRI; 3) CSF }<20 \mathrm{~cm} \mathrm{H}_{2} \mathrm{O} \text { or pos CSF tap test; } \\
\text { 4) no secondary cause }\end{array}$ & VP shunt & Retrospective \\
\hline Pinto et al., 2013 & $\begin{array}{l}\text { 1) } \geq 1 \text { of triad } \mathrm{Sx} \text {; 2) Evans index }>0.3 \text { on } \mathrm{CT} \text { or MRI; 3) CSF }<20 \mathrm{~cm} \mathrm{H}_{2} \mathrm{O} \text { or pos CSF tap test; } \\
\text { 4) no secondary cause }\end{array}$ & $\begin{array}{l}\text { VP shunt/ } \\
\text { ETV }\end{array}$ & Pro \\
\hline Oliveira et al., 2013 & $\begin{array}{l}\text { 1) } \geq 1 \text { of triad } \mathrm{Sx} \text {; 2) Evans index }>0.3 \text { on CT or MRI; 3) CSF }<20 \mathrm{~cm} \mathrm{H}_{2} \mathrm{O} \text { or pos CSF tap test; } \\
\text { 4) no secondary cause }\end{array}$ & VP shunt & Pros \\
\hline Lundin et al., 2013 & 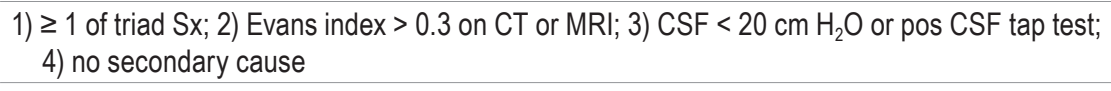 & VP shunt & Pros \\
\hline Klinge et al., 2012 & $\begin{array}{l}\text { 1) } \geq 1 \text { of triad } \mathrm{Sx} \text {; 2) Evans index }>0.3 \text { on CT or MRI; 3) CSF }<20 \mathrm{~cm} \mathrm{H}_{2} \mathrm{O} \text { or pos CSF tap test; } \\
\text { 4) no secondary cause }\end{array}$ & VP shunt & ctive \\
\hline $\begin{array}{l}\text { Bloch \& McDermott, } \\
\quad 2012\end{array}$ & 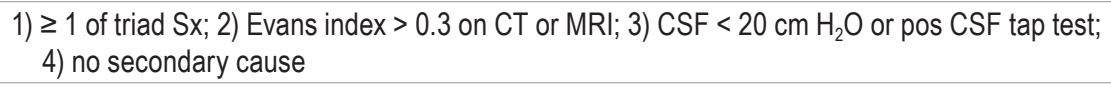 & LP shunt & Retrospective \\
\hline $\begin{array}{l}\text { Paidakakos et al., } \\
2012\end{array}$ & $\begin{array}{l}\text { 1) insidious progression over }>6 \text { mos; 2) age }>50 \mathrm{yrs} \text {; 3) }>2 \text { of triad Sx; 4) Evans index }>0.3 \\
\text { on CT or MRI; 5) no macroscopic obstruction to CSF flow }\end{array}$ & $\begin{array}{l}\text { VP shunt/ } \\
\text { ETV }\end{array}$ & Prospective \\
\hline Lundkvist et al., 2011 & $\begin{array}{l}\text { 1) age }>40 \mathrm{yrs} ; 2 \text { ) insidious onset; } 3) \mathrm{CSF}<20 \mathrm{~cm} \mathrm{H} \mathrm{H}_{2} \mathrm{O} \text { or pos CSF tap test; 4) no secondary } \\
\text { cause; 5) CSF }<20 \mathrm{~cm} \mathrm{H}_{2} \mathrm{O} \text { or pos CSF tap test }\end{array}$ & VP shunt & Retrospective \\
\hline Hashimoto et al., 2010 & $\begin{array}{l}\text { 1) age }>60 \text { yrs; 2) } \geq 1 \text { of triad } \mathrm{Sx} \text {; 3) Evans index }>0.3 \text { on } \mathrm{CT} \text { or MRI; 3) } \mathrm{CSF}<20 \mathrm{~cm} \mathrm{H}_{2} \mathrm{O} \text { or } \\
\text { pos CSF tap test; 4) no secondary cause }\end{array}$ & VP shunt & Prospective \\
\hline Gangemi et al., 2008 & $\begin{array}{l}\text { 1) } \geq 1 \text { of triad } \mathrm{Sx} \text {; 2) Evans index }>0.3 \text { on } \mathrm{CT} \text { or MRI; 3) CSF }<20 \mathrm{~cm} \mathrm{H}_{2} \mathrm{O} \text { or pos CSF tap test; } \\
\text { 4) no secondary cause }\end{array}$ & ETV & Prospective \\
\hline Hailong et al., 2008 & $\begin{array}{l}\text { 1) pos intrathecal infusion/tap test; } 2) \geq 1 \text { of triad Sx; } 3 \text { ) Evans index }>0.3 \text { on } \mathrm{CT} \text { or } \mathrm{MRI} \text {; 4) } \\
\mathrm{CSF}<20 \mathrm{~cm} \mathrm{H}_{2} \mathrm{O} \text { or pos CSF tap test; } 5 \text { ) isotope clearance impairment \& ventricular retro- } \\
\text { grade flow on radionuclide cisternography; } 6 \text { ) high-speed aqueductal flow on } \mathrm{T} 2 \mathrm{WI}\end{array}$ & ETV & Retrospective \\
\hline Pujari et al., 2008 & 1) $\geq 1$ of triad $\mathrm{Sx}$; 2) Evans index $>0.3$ on $\mathrm{CT}$ or MRI; 3) CSF $<20 \mathrm{~cm} \mathrm{H}_{2} \mathrm{O}$ or pos CSF tap test & VP shunt & Retrospective \\
\hline Spagnoli et al., 2006 & 1) $\geq 1$ of triad $\mathrm{Sx}$; 2) Evans index $>0.3$ on $\mathrm{CT}$ or $\mathrm{MRI}$; 3 ) no secondary cause & VP shunt & Prospective \\
\hline Thomas et al., 2005 & $\begin{array}{l}\text { 1) } \geq 1 \text { of triad } \mathrm{Sx} \text {; 2) ventriculomegaly on MRI or } \mathrm{CT} \text {; 3) CSF }<20 \mathrm{~cm} \mathrm{H}_{2} \mathrm{O} \text { or pos CSF tap test; } \\
\text { 4) no secondary cause }\end{array}$ & VP shunt & Prospective \\
\hline McGirt et al., 2005 & $\begin{array}{l}\text { 1) } \geq 2 \text { of triad } \mathrm{Sx} \text {; 2) Evans index }>0.3 \text { on } \mathrm{CT} \text { or } \mathrm{MRI} \text {; 3) } \mathrm{CSF}<20 \mathrm{~cm} \mathrm{H}_{2} \mathrm{O} \text { or pos CSF tap test; } \\
\text { 4) presence of } 2 \text { or more clinical features of } \mathrm{NPH} \text {; 5) no secondary cause; } 6 \text { ) either } \mathrm{A} \text { - or } \\
\text { B-waves present during artifact-free time on continuous CSF monitoring }\end{array}$ & VP shunt & Prospective \\
\hline Aygok et al., 2005 & 1) $\geq 1$ of triad $\mathrm{Sx}$; 2) Evans index $>0.3$ on $\mathrm{CT}$ or $\mathrm{MRI}$; 3) no secondary cause & VA shunt & Prospective \\
\hline
\end{tabular}

$\mathrm{Dx}=$ diagnosis; neuropsych = neuropsychological; pos = positive; $\mathrm{Sx}=$ symptom(s); T2WI = T2-weighted imaging. 
TABLE 2. Methodological quality evaluation of included studies

\begin{tabular}{|c|c|c|c|c|c|c|c|}
\hline \multirow[b]{2}{*}{ Authors \& Year } & \multicolumn{4}{|c|}{ Selection } & \multicolumn{3}{|c|}{ Outcome } \\
\hline & $\begin{array}{l}\text { Representativeness } \\
\text { of Exposed Cohort }\end{array}$ & $\begin{array}{c}\text { Selection of } \\
\text { Non-Exposed Cohort }\end{array}$ & $\begin{array}{l}\text { Ascertainment } \\
\text { of Exposure }\end{array}$ & $\begin{array}{l}\text { Study } \\
\text { Design }\end{array}$ & $\begin{array}{l}\text { Assessment } \\
\text { of Outcome }\end{array}$ & $\begin{array}{l}\text { Length Follow-Up } \\
\qquad(\geq 3 \mathrm{yrs})\end{array}$ & $\begin{array}{l}\text { Imaging Follow-Up } \\
\text { (CT, MRI) }\end{array}$ \\
\hline Craven et al., 2016 & $\bullet$ & $\bullet$ & $\bullet$ & $\bullet$ & $\bullet$ & & $\bullet$ \\
\hline Gangemi et al., 2008 & $\bullet$ & & $\bullet$ & $\bullet$ & $\bullet$ & $\bullet$ & $\bullet$ \\
\hline Kanno et al., 2017 & $\bullet$ & $\bullet$ & $\bullet$ & $\bullet$ & $\bullet$ & & $\bullet$ \\
\hline Koivisto et al., 2013 & - & $\bullet$ & - & - & $\bullet$ & $\bullet$ & \\
\hline Pinto et al., 2013 & $\bullet$ & $\bullet$ & $\bullet$ & $\bullet$ & $\bullet$ & & $\bullet$ \\
\hline Eshra, 2014 & $\bullet$ & $\bullet$ & $\bullet$ & $\bullet$ & $\bullet$ & & \\
\hline Freimann et al., 2013 & $\bullet$ & $\bullet$ & $\bullet$ & & $\bullet$ & & $\bullet$ \\
\hline Hashimoto et al., 2010 & $\bullet$ & $\bullet$ & $\bullet$ & $\bullet$ & $\bullet$ & & \\
\hline Hung et al., 2017 & $\bullet$ & $\bullet$ & $\bullet$ & & $\bullet$ & $\bullet$ & $\bullet$ \\
\hline Kazui et al., 2015 & $\bullet$ & $\bullet$ & $\bullet$ & $\bullet$ & $\bullet$ & & \\
\hline Liu et al., 2016 & $\bullet$ & $\bullet$ & $\bullet$ & & $\bullet$ & $\bullet$ & \\
\hline Lundkvist et al., 2011 & $\bullet$ & & $\bullet$ & & $\bullet$ & $\bullet$ & $\bullet$ \\
\hline Moriya et al., 2015 & $\bullet$ & $\bullet$ & $\bullet$ & $\bullet$ & $\bullet$ & & \\
\hline Klinge et al., 2012 & $\bullet$ & $\bullet$ & $\bullet$ & $\bullet$ & $\bullet$ & & \\
\hline Shaw et al., 2016 & $\bullet$ & & $\bullet$ & $\bullet$ & $\bullet$ & & $\bullet$ \\
\hline Suchorska et al., 2015 & $\bullet$ & $\bullet$ & $\bullet$ & $\bullet$ & $\bullet$ & & \\
\hline Virhammar et al., 2014 & $\bullet$ & $\bullet$ & $\bullet$ & $\bullet$ & $\bullet$ & & $\bullet$ \\
\hline Aygok et al., 2005 & $\bullet$ & & & $\bullet$ & $\bullet$ & $\bullet$ & \\
\hline Hailong et al., 2008 & $\bullet$ & & $\bullet$ & $\bullet$ & $\bullet$ & & $\bullet$ \\
\hline Lundin et al., 2013 & $\bullet$ & $\bullet$ & $\bullet$ & $\bullet$ & & & \\
\hline McGirt et al., 2005 & $\bullet$ & & $\bullet$ & $\bullet$ & $\bullet$ & & \\
\hline Nakajima et al., 2015 & $\bullet$ & $\bullet$ & $\bullet$ & & $\bullet$ & & \\
\hline Oliveira et al., 2013 & $\bullet$ & $\bullet$ & $\bullet$ & $\bullet$ & $\bullet$ & & \\
\hline Paidakakos et al., 2012 & $\bullet$ & $\bullet$ & & $\bullet$ & $\bullet$ & & \\
\hline Petersen et al., 2014 & $\bullet$ & $\bullet$ & $\bullet$ & $\bullet$ & $\bullet$ & & \\
\hline Sankey et al., 2015 & $\bullet$ & $\bullet$ & & & & • & $\bullet$ \\
\hline Tullberg et al., 2018 & $\bullet$ & & $\bullet$ & $\bullet$ & $\bullet$ & & \\
\hline $\begin{array}{l}\text { Bloch \& McDermott, } \\
2012\end{array}$ & • & $\bullet$ & $\bullet$ & & & & \\
\hline Illán-Gala et al., 2015 & $\bullet$ & & & $\bullet$ & $\bullet$ & $\bullet$ & \\
\hline Pujari et al., 2008 & - & & $\bullet$ & & $\bullet$ & $\bullet$ & \\
\hline Spagnoli et al., 2006 & $\bullet$ & & $\bullet$ & $\bullet$ & $\bullet$ & & \\
\hline Thomas et al., 2005 & $\bullet$ & & & $\bullet$ & $\bullet$ & & \\
\hline Thompson et al., 2017 & $\bullet$ & & & & $\bullet$ & & $\bullet$ \\
\hline
\end{tabular}

in 4 (150 patients). In 3 studies, outcomes of different CSF diversion techniques were compared for a total of 582 patients. In these studies, patients were treated with VP shunting in 400 cases, VA shunting in 150, and ETV in 32. In 12 studies, follow-up ranged from 3 to 12 months postoperatively; in 14 studies, it ranged from 12 to 36 months; and in 7 studies, last follow-up was more than 36 months.

\section{Extracranial Shunts}

Outcomes

Data on outcomes and complications are summarized in Table 3. The overwhelming majority of patients who underwent extracranial CSF shunting (almost 90\%) had a programmable valve placed. Approximately 25\% of those valves were Codman Hakim valves (Codman Neuro), 15\% were Miethke proGAV valves (Aesculap), and $<10 \%$ were Strata valves (Medtronic). In the remainder of cases, the type of programmable valve used was not specified. Antisiphon or antigravitational devices were present in approximately $35 \%$ of the shunt systems.

A decline in the proportion of patients who improved clinically was found when comparing patients followed for less than 12 months $(78 \%, 95 \%$ CI $74 \%-82 \%)$ to those followed for 12 to 36 months $(73 \%, 95 \%$ CI 69\%-78\%). This decline was even more pronounced for patients who were reevaluated after 36 months (71\%, 95\% CI 62\%-69\%). 
TABLE 3. Summary of outcomes and adverse events for each treatment modality

\begin{tabular}{|c|c|c|c|c|}
\hline Outcome or Adverse Event & VP Shunt & VA Shunt & LP Shunt & Any Extracranial Shunt* \\
\hline Overall outcome & $75(71-79)$ & 77 (72-82) & $76(69-82)$ & $76(73-79)$ \\
\hline Gait improvement & $72(61-82)$ & $64(55-74)$ & $100(90-100)$ & $75(65-84)$ \\
\hline Cognitive impairment & $61(54-68)$ & $63(52-73)$ & $55(34-74)$ & $62(55-68)$ \\
\hline Incontinence & $54(28-78)$ & $59(48-70)$ & $46(30-64)$ & $55(39-71)$ \\
\hline Subdural collections & $10(6-12)$ & $10(3-20)$ & $7(3-12)$ & $9(7-12)$ \\
\hline Ischemic/hemorrhagic event & $2(1-4)$ & $2(1-3)$ & $7(3-15)$ & $2(1-4)$ \\
\hline Postop infections & $3(1-5)$ & $2(1-4)$ & NA & $2(2-3)$ \\
\hline Postop seizures & NA & $2 \dagger$ & NA & 2 \\
\hline Revision & $18(13-24)$ & $12 \dagger$ & $14(5-26)$ & $16(12-22)$ \\
\hline Mortality & $1.5(0.5-4.2)$ & NA & NA & $1.5(0.5-4.2)$ \\
\hline \multicolumn{5}{|c|}{$\begin{array}{l}\text { NA = not applicable. } \\
\text { Rates for VP shunts are based on } 23 \text { studies ( } 1812 \text { patients). Rates for VA shunts are based on } 3 \text { studies ( } 258 \text { patients). Rates for LP shunts are } \\
\text { based on } 4 \text { studies ( } 209 \text { patients). } \\
\text { *VA, VP, or LP. } \\
\text { † These data come from a single series and therefore were not pooled in the meta-analysis. }\end{array}$} \\
\hline
\end{tabular}

Overall, the proportion of patients who experienced a favorable outcome after shunting was 76\% (95\% CI 73\%$76 \%)$. Stratification by treatment type showed that a favorable outcome was reported for $75 \%$ (95\% CI 71\%-79\%) of patients after VP shunting, 77\% (95\% CI 72\%-82\%) after VA shunting, and 76\% (95\% CI 69\%-82\%) after LP shunting (Fig. 2). We subsequently conducted sensitivity analysis comparing patients who had improvement measured using Hakim's triad criteria to patients who had improvement measured using clinical scores. The difference in improvement between the groups was not significant (Hakim: 76\%, 95\% CI 72\%-79\% vs clinical: 72\%, 95\% CI 65\%-78\%).

Overall, gait improvement was observed in $75 \%$ of patients after CSF shunting. When the data were stratified by treatment type, gait improvement occurred in $72 \%$ (95\% CI $61 \%-82 \%$ ) of patients treated with VP shunts, in $64 \%$ (95\% CI 55\%-74\%) of those treated with VA shunts, and in $90 \%$ (95\% CI 90\%-100\%) of those treated with LP shunts. Improvement in cognitive function was observed in $62 \%$ of patients overall. Cognitive function improvement was observed in $61 \%$ (95\% CI 54\%-68\%) of patients after VP shunting, in $63 \%$ (95\% CI 52\%-77\%) of patients after VA shunting, and in 55\% (95\% CI 34\%-74\%) of patients after LP shunting. Overall, urinary incontinence improved in $55 \%$ of patients. When categorized according to treatment type, urinary improvement occurred in 54\% $(95 \%$ CI $28 \%-78 \%$ ) of patients treated with VP shunts, in $59 \%$ $(95 \%$ CI $48 \%-70 \%)$ of those treated with VA shunts, in $46 \%$ (95\% CI 30\%-64\%) of those treated with LP shunts, and in 50\% (95\% CI 38\%-62\%) of those treated with ETV.

\section{Complications}

Postoperative subdural hematomas or hygromas were as likely to occur after VA shunt placement $(10 \%, 95 \%$ CI $3 \%-20 \%)$ as after placement of VP shunts $(10 \%, 95 \%$ CI $6 \%-12 \%)$ or LP shunts $(7 \%, 95 \%$ CI $3 \%-12 \%)$. Following shunt placement, $9 \%$ of patients developed a subdural collection (Fig. 3). Approximately $85 \%$ of subdural collections regressed spontaneously after the valve opening pressure was increased, and less than $15 \%$ required surgical evacuation. Nearly $40 \%$ of the subdural collections were hygromas, and $4 \%$ of those hygromas required surgery. Overall, only $2 \%$ of patients had ischemic or hemorrhagic complications following shunt placement; stratified by shunt type, postoperative ischemic or hemorrhagic complications were reported in $2 \%$ (95\% CI $1 \%-4 \%$ ) of patients treated with VP shunts, $2 \%(95 \%$ CI $1 \%-3 \%)$ of those treated with VA shunts, and 7\% (95\% CI 3\%-15\%) of those treated with LP shunt.

The overall infection rate for shunt-treated patients was $2 \%$. When stratified by treatment type, the postoperative infection rates were $3 \%(95 \%$ CI $1 \%-5 \%)$ for VP shunting and $2 \%(95 \%$ CI $1 \%-4 \%)$ for VA shunting. No data about infection rates after LP shunting were available in the included series. Postoperative seizures occurred in $2 \%$ of patients undergoing VA shunting. No data were available about postoperative seizures rates in the included VP series.

\section{Revisions}

Among all shunt-treated patients, $16 \%$ underwent surgical revision, due to treatment failure, infection, or shunt malfunction, over a follow-up period of 3 to 192 months (Fig. 4). Stratification by treatment type showed that surgical revision was performed in $18 \%$ (95\% CI 13\%-24\%) of VP shunt-treated patients over a mean follow-up time of 3 to 78 months, in $12 \%$ (95\% CI 6\%-23\%) of VA shunttreated patients over a mean follow-up of 192 months, and in $14 \%$ (95\% CI $5 \%-26 \%)$ of LP shunt-treated patients over a mean follow-up time of 12 months. Around $10 \%$ of surgical revisions were a consequence of treatment failure. About $40 \%$ of shunt-treated patients had symptoms of overdrainage, though most of these patients were treated with shunt reprogramming.

\section{Mortality}

Mortality was estimated to be less than $2 \%$ (95\% CI $0.5 \%-4.2 \%$ ) among shunt-treated patients during the im- 


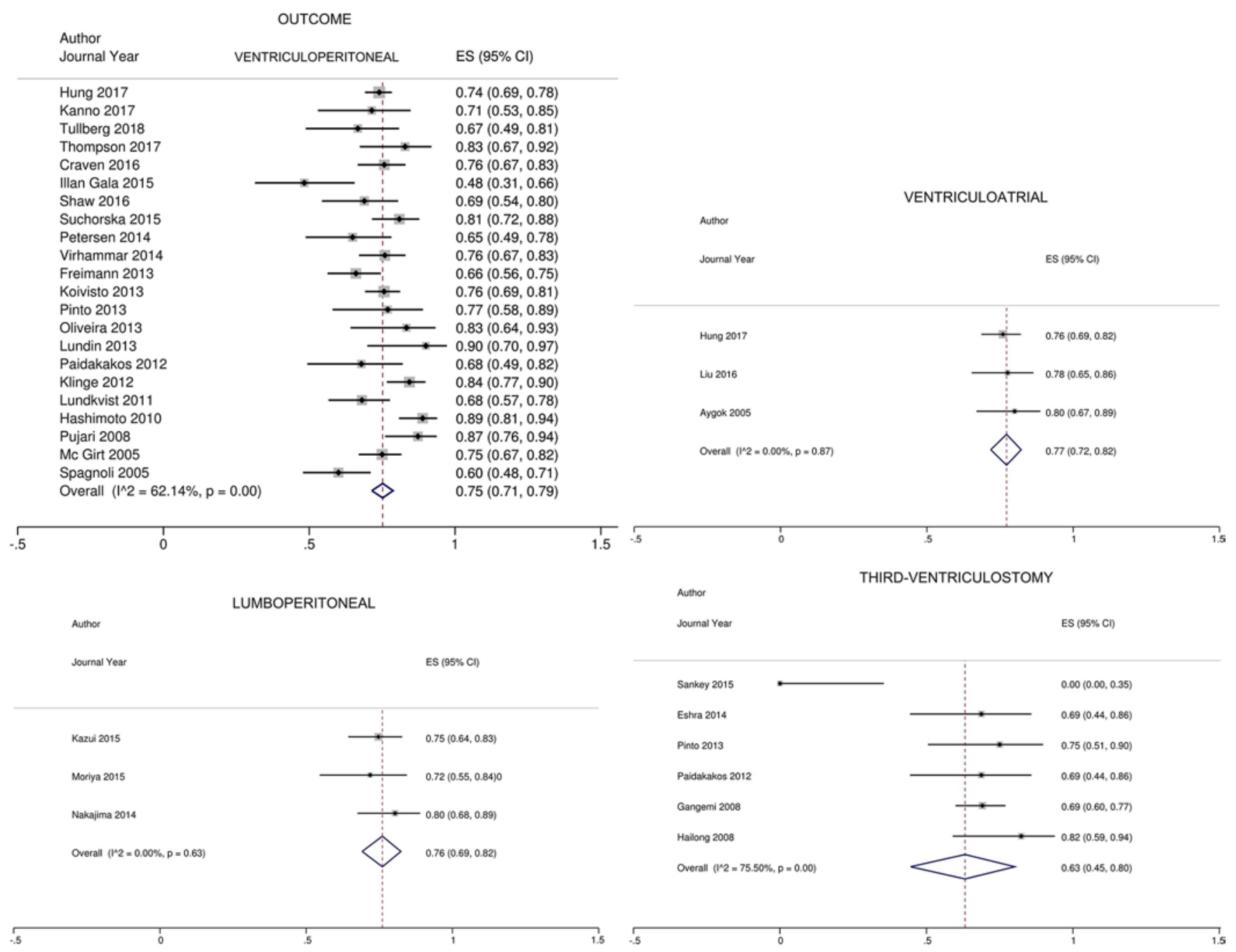

FIG. 2. Forest plot for overall improved outcome for iNPH patients. ES = effect size. Figure is available in color online only.

mediate postoperative period. The cause of perioperative death was related to the shunt placement procedure in the majority (75\%) of cases (lobar hemorrhages along the catheter track or surgical site infection).

Analyzing the treatment efficacy and complications over the last 12 years did not show a trend toward improvement of outcomes or reduction of subdural collections, even after stratification by the type of valves implanted. However, a reduction of revisions was observed over these time periods. Characteristics of studies included in the extracranial shunt analysis are summarized in Table 4.

\section{Adjustable Versus Fixed-Pressure Valves}

Overall outcome was similar in patients with programmable valves $(74 \%, 95 \%$ CI $71 \%-78 \%)$ and those with fixed-pressure valves $(76 \%, 95 \%$ CI $70 \%-82 \%)$. Nonsignificant differences were found between programmable valves with antisiphon/antigravity components (72\%, 95\% CI 67\%-77\%) and those without $(77 \%, 95 \%$ CI $72 \%-82 \%)$. However, the proportion of any subdural collection with programmable valves was much lower $(9 \%$,
$95 \%$ CI 6\%-12\%) than that with fixed valves $(22 \%, 95 \%$ CI $11 \%-34 \%)$. Only a mild difference in the proportion of subdural collections was found comparing programmable valves with antisiphon/antigravity components $(6 \%, 95 \%$ CI $2 \%-13 \%)$ to programmable valves alone $(10 \%, 95 \%$ CI $7 \%-13 \%)$.

Similarly, over a period of 12 years, shunting with programmable valves resulted in a significantly lower proportion of revisions $(12 \%, 95 \%$ CI 9\%-16\%) compared to shunting with fixed-pressure valves $(32 \%, 95 \%$ CI $26 \%-$ $38 \%$ ). No difference in revision proportion was found between valves with antisiphon/antigravity components $(13 \%, 95 \%$ CI $8 \%-18 \%)$ and those without $(13 \%, 95 \%$ CI $8 \%-18 \%$ ). Eventually, when comparing the estimated proportion of patients whose condition improved in series in which patients were treated before 2005 (from 1990 to $2005)$ to that in series in which patients were treated from 2005 to 2017, there were no significant differences $(76 \%$ vs $74 \%$, respectively) in outcomes. However, the need for revision surgeries dropped significantly (12\% vs $31 \%)$ over the last 12 years. 


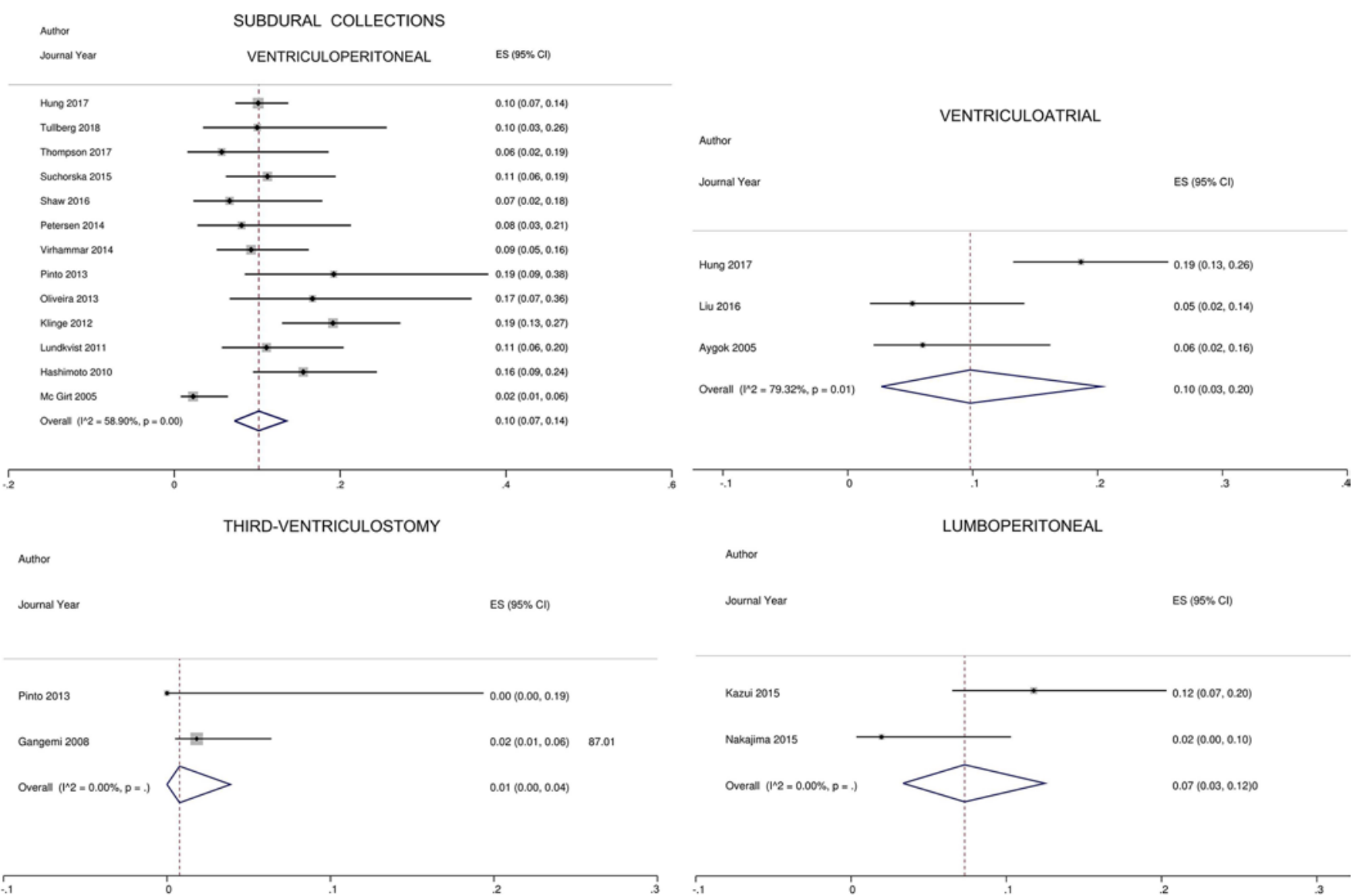

FIG. 3. Forest plot for the proportion of patients with subdural collections. Figure is available in color online only.

\section{Endoscopic Third Ventriculostomy}

Overall, the proportion of patients who experienced a favorable outcome after ETV was 63\% (95\% CI 45\%$80 \%$ ). When comparing the proportion of patients who improved based on functional grading scales or clinical rating scales, gait improvement was 79\% (95\% CI 71\%$87 \%$ ), improvement in cognitive function occurred in only $20 \%$ of cases after ETV (95\% CI 11\%-32\%), while urinary incontinence improved in $50 \%$ of patients $(95 \%$ CI $38 \%-62 \%$ ).

Patients who underwent ETV had a low proportion of subdural collections $(1 \%, 95 \%$ CI $0 \%-4 \%)$, and revision surgery was required in $16 \%$ (95\% CI $4 \%-33 \%$ ) of ETV cases (follow-up time 12 to 80 months). Of ETV patients who required revision, more than $50 \%$ subsequently underwent VP shunt placement.

\section{Discussion}

To the best of our knowledge, this is the most up-to-date and extensive systematic review and meta-analysis on outcomes and complications of different surgical treatments for iNPH. We compared outcomes and adverse events between the most common types of shunting procedures (VP vs LP vs VA), both separately and together, with particular emphasis on shunt valve type and antisiphon device use. Compared to previous reviews that included studies published before 2005, inclusion criteria in this analysis were based on the most recent guidelines, including an age cutoff of 60 years. As most patients in previous reviews were treated prior to release of the 2012 Japanese iNPH guidelines,${ }^{32,35}$ younger patients ( $<50$ years) were included in these reviews, which is a major limitation, as it could have led to inclusion of patients with congenital arrested hydrocephalus. We also analyzed outcomes after ETV treatment, although those results should be interpreted with caution because of the limited sample size and the fact that most of the studies did not meet our inclusion criteria. Therefore, as no prior meta-analyses on iNPH have included ETV data, in an effort to still present a comprehensive view of current iNPH treatment, we present these studies with descriptive statistics only.

In our analysis, more than $75 \%$ of patients had improvement in their condition after shunting, without significant differences regarding the type of extracranial procedure used. ${ }^{20,21,37,50,58}$ In contrast to authors of previous studies, ${ }^{55}$ we did not find any differences in symptom outcomes after shunting over the last 2 decades. This observation may suggest that, once the shunt is working and patients are adequately selected, outcomes of the procedure do not change over time, with an estimated rate of success stable around $75 \% .{ }^{33}$ We also found a mild clinical deterioration of estimated outcomes with longer follow-up. Although advances in valves and shunt technologies did not signifi- 


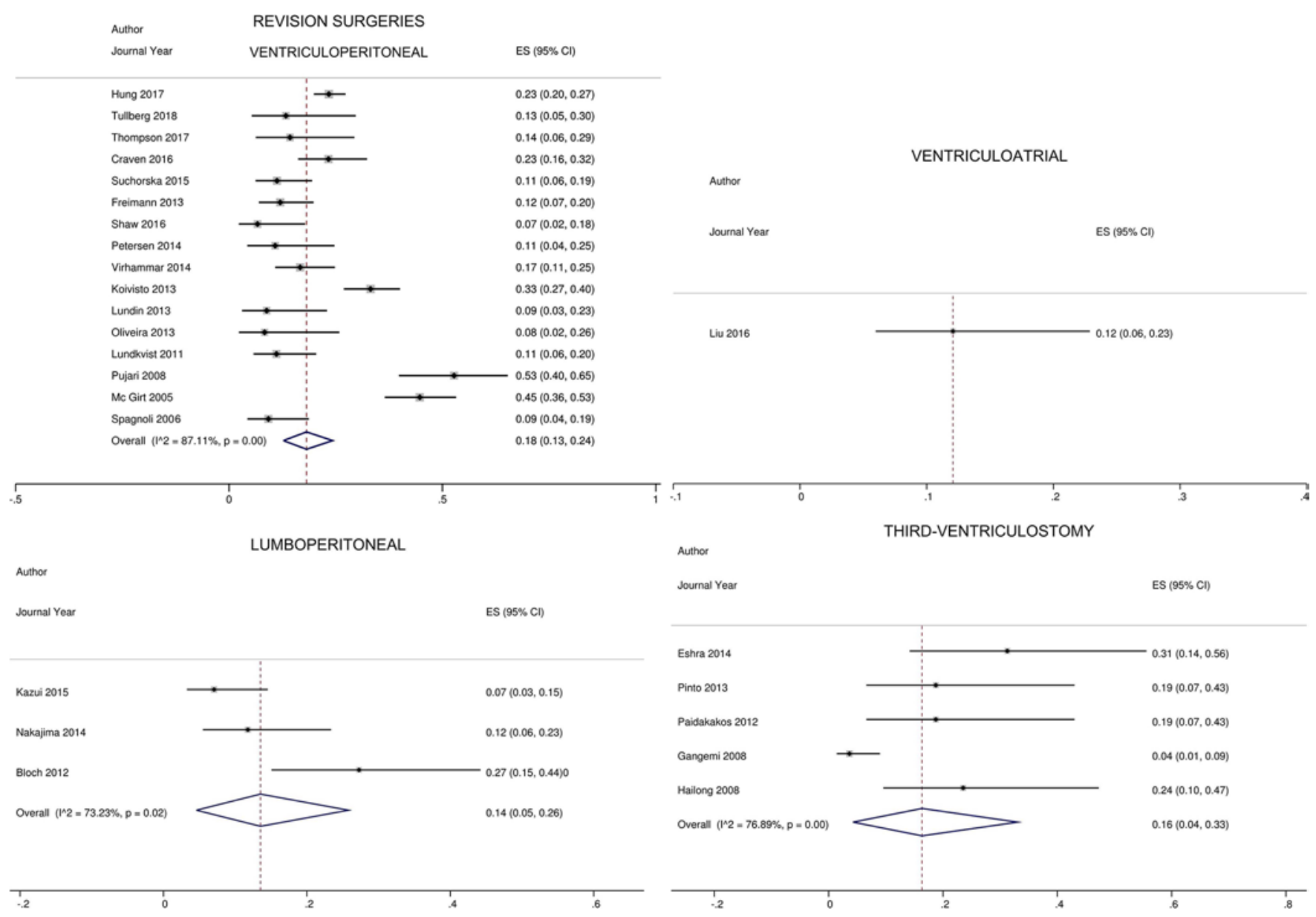

FIG. 4. Forest plot for the proportion of patients who underwent surgical revision. Figure is available in color online only.

cantly affect outcomes in gait, cognition, and urinary incontinence, there was a significant effect on the incidence of adverse events and the need for revision. In the current focus on value-based care, the significantly increased cost of a programmable valve may be justified by the reduction in the need for revision related to valve exchange from $32 \%$ to $12 \%$ over the past 2 decades.

Among NPH symptoms, cognitive improvement responds less favorably, while gait ataxia often progressively improves $^{48}$ over the first 3-6 months. ${ }^{18,19,39,41,43,48,53}$ Gait amelioration is reported in $80 \%-83 \%$ of patients 3 years after VP shunting and in $87 \%$ of patients after 7 years..$^{24,26}$, ${ }^{29,43}$ Comparable results were reported for patients treated with $\mathrm{VA}^{44,51}$ and LP shunts. 2,37,38 We found that cognitive function improved in more than $50 \%$ of patients who underwent shunting, with nonsignificant differences regarding the types of shunt used.

A $>50 \%$ improvement of incontinence after extracranial shunting was found in this study. Urinary continence improvement has been reported in almost $50 \%$ of patients treated with LP shunts, ${ }^{3}$ in $50 \%-77 \%$ of those treated with VA shunts, $, 16,28$ and in $66 \%-84 \%$ of those treated with VP shunts. ${ }^{23,43,52}$

Adverse events can range from headache to life-threatening intraparenchymal or subdural hematomas requiring surgical evacuation. ${ }^{3}$ Complication rates for patients treated with VP shunts ranged from $13 \%$ to $38 \%$, the majority occurring within the 1 st year after surgery. ${ }^{12,17}$ It was also estimated that $20 \%-33 \%$ of patients treated with VP shunts required additional surgery, with $15 \%$ undergoing shunt revision during a 1-year period (median time to second intervention: 73.5 months). ${ }^{15,38,42,54}$ We estimated a lower rate of revision surgeries, especially when considering patients treated in the last 10 years; this difference could potentially be explained as a consequence of improved shunt technology. No differences in the rates of postoperative infections, ischemic or hemorrhagic events, or seizures were found in relation to the type of procedure considered.

There were no significant differences between VP, VA, or LP shunts with respect to revision rates. Subdural hematoma is a common complication after shunt insertion; modern iNPH series reporting nontraumatic subdural collection rates of $0 \%-16 \%{ }^{57}$ and rates of $5.6 \%{ }^{52}$ and $7 \% 3$ have been reported for collections requiring surgical evacuation. Based on the data in this meta-analysis, most subdural hematomas regressed spontaneously after increasing the valve working pressure, with only $10 \%$ of cases requiring surgical evacuation. A few subdural fluid collections were hygromas, less than $5 \%$ of which needed surgical evacuation. 
TABLE 4. Characteristics of studies included in the analysis of outcome and adverse events for extracranial shunts and ETV

\begin{tabular}{|c|c|c|c|c|}
\hline & $\begin{array}{l}\text { No. of } \\
\text { Studies }\end{array}$ & $\begin{array}{c}\text { Total } \\
\text { Sample } \\
\text { Size }\end{array}$ & $1^{2 *}$ & $\begin{array}{c}\text { Study } \\
\text { Design (pro-/ } \\
\text { retrospective) }\end{array}$ \\
\hline \multicolumn{5}{|l|}{ Extracranial shunts } \\
\hline \multicolumn{5}{|l|}{ Outcomes analysis } \\
\hline Overall outcome & 27 & 2194 & 54.3 & $19 / 8$ \\
\hline Gait & 11 & 830 & 89.4 & $8 / 3$ \\
\hline Cognitive & 9 & 424 & 45.3 & $5 / 4$ \\
\hline Urinary & 7 & 415 & 90.4 & $4 / 3$ \\
\hline \multicolumn{5}{|l|}{ Complication analysis } \\
\hline Infection & 16 & 1500 & 28.9 & $10 / 6$ \\
\hline Ischemic/hemorrhagic & 6 & 931 & 56.5 & $5 / 1$ \\
\hline Subdural & 17 & 1493 & 63.6 & $12 / 5$ \\
\hline Revision & 22 & 1845 & 87.1 & $11 / 11$ \\
\hline Mortality & 4 & 230 & NA & $4 / 0$ \\
\hline \multicolumn{5}{|l|}{ ETV } \\
\hline \multicolumn{5}{|l|}{ Outcomes analysis } \\
\hline Overall outcome & 6 & 182 & 75.5 & $4 / 2$ \\
\hline Gait & 2 & 106 & NA & $2 / 0$ \\
\hline Cognitive & 2 & 66 & NA & $2 / 0$ \\
\hline Urinary & 2 & 76 & NA & $2 / 0$ \\
\hline Complication analysis & 2 & 126 & NA & $2 / 0$ \\
\hline Subdural & 2 & 126 & NA & $2 / 0$ \\
\hline Revision & 5 & 175 & 76.9 & $4 / 1$ \\
\hline
\end{tabular}

${ }^{*}$ Measure of heterogeneity among studies (percentage of variation due to heterogeneity).

Infection is considered the second most common complication, with a prevalence $(3 \%-12 \%)$ that has not been shown to change with the type of shunt used. Based on the results of this meta-analysis, the rates of infections did not differ significantly among different extracranial shunt types. Permanent neurological deficits and death from significant intracranial hemorrhage or ischemic events are uncommon $(1 \%-6 \%)$, and the risk of intraparenchymal hematoma from ventricular catheter placement has been estimated as approximately $1 \% .^{3}$ Mortality rates reported in the literature range from $0 \%$ to $3 \% .^{15}$ This meta-analysis showed values in line with data reported in the literature.

In this study, the number of patients who had subdural collections and required revision surgeries was almost cut in half in studies with adjustable valves (compared to the rate with fixed-pressure valves). ${ }^{30,39} \mathrm{~A}$ further decline in the proportion of patients with adverse events was found when antisiphon/antigravity components were added..$^{10}$ Programmable valves were designed to easily allow for changes in working pressure, avoiding or correcting overdrainage, and thereby decreasing the occurrence of subdural collections and revision. A shift from fixed-pressure to programmable valves became evident in the early $2000 \mathrm{~s},{ }^{4}$ along with a progression in shunt technology over the last 15 years. Moreover, around 2005, antisiphon/antigravity components were added to some valve mechanisms, or as add-on devices, to avoid undesired changes in CSF drainage during postural changes. Based on these benefits, programmable valves are often preferred over fixed-pressure valves in the iNPH population. Adjustable valves allow for noninvasive changing of opening pressure, resulting in a reduced rate of overdrainage, with potentially fewer subdural collections requiring surgery. ${ }^{23}$ The average number of valve adjustments required to achieve the final clinically optimized setting has been estimated at 1.7 in one study ${ }^{31}$ and 3.1 in another. ${ }^{39}$ Also, with the addition of antigravitational components, a decrease (by 90\%) in the rate of subdural collection formation and overdrainage symptoms has been described..$^{52,56}$ In the included studies, almost all authors preferred to use adjustable valves, with a tendency to set high working pressures to guard against overdrainage, decreasing the setting later if necessary. The few that still used fixed-pressure valves carefully selected patients for surgery and set the working pressure between 6 and $10 \mathrm{~cm} \mathrm{H}_{2} \mathrm{O}$. As stated above, these data indicate that there may be added value in the use of programmable valves due to the reduction in costs associated with reoperation and adverse events despite a much higher initial valve cost, though a formal cost analysis should be performed to more thoroughly investigate this topic in the future.

Compared to VP shunts, VA shunts potentially reduce operative time, because of a modified percutaneous Seldinger technique, ${ }^{49}$ and allow easier visualization of the distal catheter intraoperatively. VA shunts should be considered an effective alternative to VP shunts when managing iNPH. ${ }^{28}$ The same consideration could be made for LP shunts, which have been demonstrated to have similar results when compared to VP and VA shunts. ${ }^{5,12,14}$

ETV is primarily reserved for treating hydrocephalus of obstructive etiologies, but it has been explored previously as a treatment for iNPH. ${ }^{13,40} \mathrm{~A}$ major criticism is that most ETV series involving patients with iNPH used CT rather than high-definition MRI and therefore likely included patients with obstructive etiologies, such as arrested congenital hydrocephalus, rather than true iNPH diagnoses. Notably, more than $50 \%$ of ETV patients required revision surgery; thus, ETV should not be considered a first-line therapy for true iNPH. The proportions of ETV-treated patients who showed improvement in gait and urinary incontinence $(75 \% \text { and } 50 \% \text { of patients, respectively) })^{8,11}$ are similar to the corresponding rates for shunt-treated patients. These findings could reinforce the theory that ventriculomegaly represents a neuroradiological finding within a spectrum of neurodegenerative disorders, ${ }^{9}$ or it is possible that the studies included some patients with a more long-standing obstructive etiology. In addition, the proportion of patients with subdural collections was lower after ETV, potentially due to less actual diversion of CSF than with shunting in this patient population.

Almost all of the ETV procedures described in this meta-analysis were performed with a rigid endoscope. Although ETV has always been considered more effective in the management of hydrocephalus related to obstructive rather than communicating etiologies, clinical improvement (up to $66 \%-75 \%$ of patients) was observed in a series of patients who underwent ETV with better late outcomes and a lower rate of overdrainage when compared to shunt- 
treated patients. ${ }^{8,34,45}$ This trend seems to be in line with what was estimated in this meta-analysis. However, it is possible that many studies on ETV are affected by a selection bias, as high-definition MRI to rule out aqueductal stenosis or fourth ventricle outflow obstruction was not routinely performed. It has been found that more than $10 \%$ of patients with a presumed diagnosis of iNPH actually have infratentorial, intracisternal obstructive hydrocephalus on MRI. ${ }^{7,22,47}$ In patients who did not initially improve after ETV, shunting is recommended, with an estimated $50 \%$ outcomes improvement after a second surgery. ${ }^{42}$

The main limitation of our analysis is the lack of individual patient data, which makes prognostic analysis subject to confounding bias. In addition, 11 studies were estimated to have an elevated risk of bias. Furthermore, iNPH outcomes were assessed with a nonuniform grading system, possibly introducing a selection bias. There was also the chance of an inter- and intraobserver variability in assessing the prevalence of improvement, especially regarding gait, cognitive function, and continence outcomes. Because there are no universally accepted scales to evaluate the outcomes and adverse events, selection bias is very likely to occur. Also, not all of the studies reported every outcome assessed in this review. Finally, there was a disproportionate number of studies when considering each treatment strategy. VP shunts are more commonly reported in the literature than are VA and LP shunts and ETV. Although this may have impacted the results, every attempt was made to account for heterogeneity using statistical methods. Moreover, studies included in this metaanalysis were selected following an a priori established protocol, the literature search included multiple databases, and study selection was rigorous and based on the criteria established by the most recent guidelines.

A universally accepted and applied grading system for evaluating outcomes after treatment of iNPH has not been established yet. This makes comparisons between different series difficult, especially when assessing cognitive outcome. Therefore, it is critical to advance knowledge on this controversial topic to utilize consistent and accepted definitions and outcome measures and to establish large observational prospective registries with unified criteria.

\section{Conclusions}

This meta-analysis highlighted that outcomes for iNPH treatment did not change significantly between VP, VA, and LP shunting, with an estimated improvement in more than $75 \%$ of patients. ETV was not found to be significantly less effective than extracranial shunting in reverting iNPH symptoms, though it is not clear that the patients successfully treated with ETV in the included studies actually had a true iNPH diagnosis. With respect to adverse events, no differences were found between different treatment strategies, except for an almost negligible rate of patients experiencing subdural collections after ETV. Most interestingly, in concomitance with the shifting from fixed to adjustable valves, there was a clear decline in surgery-related complications. This decline was particularly evident for a reduction in revision surgeries, potentially justifying the increased cost associated with the use of programmable valves. Based on this meta-analysis, VP, VA, and LP shunting with a programmable valve all appear to be suitable first-line treatments for iNPH in adequately selected patients.

\section{References}

1. Aygok G, Marmarou A, Young HF: Three-year outcome of shunted idiopathic NPH patients. Acta Neurochir Suppl 95:241-245, 2005

2. Bayar MA, Tekiner A, Celik H, Yilmaz A, Menekse G, Yildirim T, et al: Efficacy of lumboperitoneal shunting in patients with normal pressure hydrocephalus. Turk Neurosurg 28:62-66, 2018

3. Bloch O, McDermott MW: Lumboperitoneal shunts for the treatment of normal pressure hydrocephalus. J Clin Neurosci 19:1107-1111, 2012

4. Boon AJ, Tans JT, Delwel EJ, Egeler-Peerdeman SM, Hanlo PW, Wurzer HA, et al: Dutch Normal-Pressure Hydrocephalus Study: randomized comparison of low- and mediumpressure shunts. J Neurosurg 88:490-495, 1998

5. Craven CL, Toma AK, Mostafa T, Patel N, Watkins LD: The predictive value of DESH for shunt responsiveness in idiopathic normal pressure hydrocephalus. J Clin Neurosci 34:294-298, 2016

6. DerSimonian R, Kacker R: Random-effects model for metaanalysis of clinical trials: an update. Contemp Clin Trials 28:105-114, 2007

7. Dlouhy BJ, Capuano AW, Madhavan K, Torner JC, Greenlee JD: Preoperative third ventricular bowing as a predictor of endoscopic third ventriculostomy success. J Neurosurg Pediatr 9:182-190, 2012

8. Eshra MA: Endoscopic third ventriculostomy in idiopathic normal pressure hydrocephalus. Alexandria J Med 50:341344, 2014

9. Espay AJ, Da Prat GA, Dwivedi AK, Rodriguez-Porcel F, Vaughan JE, Rosso M, et al: Deconstructing normal pressure hydrocephalus: ventriculomegaly as early sign of neurodegeneration. Ann Neurol 82:503-513, 2017

10. Freimann FB, Vajkoczy P, Sprung C: Patients benefit from low-pressure settings enabled by gravitational valves in normal pressure hydrocephalus. Clin Neurol Neurosurg 115:1982-1986, 2013

11. Gangemi M, Maiuri F, Naddeo M, Godano U, Mascari C, Broggi G, et al: Endoscopic third ventriculostomy in idiopathic normal pressure hydrocephalus: an Italian multicenter study. Neurosurgery 63:62-69, 2008

12. Gölz L, Ruppert FH, Meier U, Lemcke J: Outcome of modern shunt therapy in patients with idiopathic normal pressure hydrocephalus 6 years postoperatively. J Neurosurg 121:771-775, 2014

13. Hailong F, Guangfu H, Haibin T, Hong P, Yong C, Weidong $\mathrm{L}$, et al: Endoscopic third ventriculostomy in the management of communicating hydrocephalus: a preliminary study. J Neurosurg 109:923-930, 2008

14. Hashimoto M, Ishikawa M, Mori E, Kuwana N: Diagnosis of idiopathic normal pressure hydrocephalus is supported by MRI-based scheme: a prospective cohort study. Cerebrospinal Fluid Res 7:18, 2010

15. Hebb AO, Cusimano MD: Idiopathic normal pressure hydrocephalus: a systematic review of diagnosis and outcome. Neurosurgery 49:1166-1186, 2001

16. Hughes CP, Siegel BA, Coxe WS, Gado MH, Grubb RL, Coleman RE, et al: Adult idiopathic communicating hydrocephalus with and without shunting. J Neurol Neurosurg Psychiatry 41:961-971, 1978

17. Hung AL, Vivas-Buitrago T, Adam A, Lu J, Robison J, Elder $\mathrm{BD}$, et al: Ventriculoatrial versus ventriculoperitoneal shunt complications in idiopathic normal pressure hydrocephalus. Clin Neurol Neurosurg 157:1-6, 2017 
18. Illán-Gala I, Pérez-Lucas J, Martín-Montes A, MáñezMiró J, Ruiz-Ares G, Díez-Tejedor E: Long-term follow-up of idiopathic normal pressure hydrocephalus treated with ventriculo-peritoneal programmable valve. Eur J Neurol 22:122-123, 2015 (Abstract)

19. Junkkari A, Häyrinen A, Rauramaa T, Sintonen H, Nerg O, Koivisto AM, et al: Health-related quality-of-life outcome in patients with idiopathic normal-pressure hydrocephalus-a 1-year follow-up study. Eur J Neurol 24:58-66, 2017

20. Kanno S, Saito M, Kashinoura T, Nishio Y, Iizuka O, Kikuchi H, et al: A change in brain white matter after shunt surgery in idiopathic normal pressure hydrocephalus: a tractbased spatial statistics study. Fluids Barriers CNS 14:1, 2017

21. Kazui H, Miyajima M, Mori E, Ishikawa M: Lumboperitoneal shunt surgery for idiopathic normal pressure hydrocephalus (SINPHONI-2): an open-label randomised trial. Lancet Neurol 14:585-594, 2015

22. Kehler U, Gliemroth J: Extraventricular intracisternal obstructive hydrocephalus-a hypothesis to explain successful 3 rd ventriculostomy in communicating hydrocephalus. Pediatr Neurosurg 38:98-101, 2003

23. Klinge P, Hellström P, Tans J, Wikkels $\varnothing$ C: One-year outcome in the European multicentre study on iNPH. Acta Neurol Scand 126:145-153, 2012

24. Koivisto AM, Alafuzoff I, Savolainen S, Sutela A, Rummukainen J, Kurki M, et al: Poor cognitive outcome in shunt-responsive idiopathic normal pressure hydrocephalus. Neurosurgery 72:1-8, 2013

25. Kubo Y, Kazui H, Yoshida T, Kito Y, Kimura N, Tokunaga $\mathrm{H}$, et al: Validation of grading scale for evaluating symptoms of idiopathic normal-pressure hydrocephalus. Dement Geriatr Cogn Disord 25:37-45, 2008

26. Lemcke J, Meier U: Idiopathic normal pressure hydrocephalus (iNPH) and co-morbidity: an outcome analysis of 134 patients. Acta Neurochir Suppl 114:255-259, 2012

27. Liberati A, Altman DG, Tetzlaff J, Mulrow C, Gøtzsche PC, Ioannidis JP, et al: The PRISMA statement for reporting systematic reviews and meta-analyses of studies that evaluate healthcare interventions: explanation and elaboration. BMJ 339:b2700, 2009

28. Liu A, Sankey EW, Jusué-Torres I, Patel MA, Elder BD, Goodwin CR, et al: Clinical outcomes after ventriculoatrial shunting for idiopathic normal pressure hydrocephalus. Clin Neurol Neurosurg 143:34-38, 2016

29. Lundin F, Ledin T, Wikkels $\varnothing$ C, Leijon G: Postural function in idiopathic normal pressure hydrocephalus before and after shunt surgery: a controlled study using computerized dynamic posturography (EquiTest). Clin Neurol Neurosurg 115:1626-1631, 2013

30. Lundkvist B, Koskinen LO, Birgander R, Eklund A, Malm J: Cerebrospinal fluid dynamics and long-term survival of the Strata valve in idiopathic normal pressure hydrocephalus. Acta Neurol Scand 124:115-121, 2011

31. Ma TS, Sharma N, Grady MS: A simplified pressure adjustment clinical pathway for programmable valves in NPH patients. Clin Neurol Neurosurg 159:83-86, 2017

32. Marmarou A, Bergsneider M, Klinge P, Relkin N, Black PML: The value of supplemental prognostic tests for the preoperative assessment of idiopathic normal-pressure hydrocephalus. Neurosurgery 57 (3 Suppl):S17-S28, ii-v, 2005

33. McGirt MJ, Woodworth G, Coon AL, Thomas G, Williams MA, Rigamonti D: Diagnosis, treatment, and analysis of long-term outcomes in idiopathic normal-pressure hydrocephalus. Neurosurgery 57:699-705, 2005

34. Meier U: Outcome of idiopathic normal-pressure hydrocephalus after surgery with gravity valves. Neurosurg $\mathbf{Q}$ 14:119-126, 2004

35. Mori E, Ishikawa M, Kato T, Kazui H, Miyake H, Miyajima
M, et al: Guidelines for management of idiopathic normal pressure hydrocephalus: second edition. Neurol Med Chir (Tokyo) 52:775-809, 2012

36. Mori K: Management of idiopathic normal-pressure hydrocephalus: a multiinstitutional study conducted in Japan. J Neurosurg 95:970-973, 2001

37. Moriya M, Miyajima M, Nakajima M, Ogino I, Arai H: Impact of cerebrospinal fluid shunting for idiopathic normal pressure hydrocephalus on the amyloid cascade. PLoS One 10:e0119973, 2015

38. Nakajima M, Miyajima M, Ogino I, Sugano H, Akiba C, Domon N, et al: Use of external lumbar cerebrospinal fluid drainage and lumboperitoneal shunts with Strata NSC valves in idiopathic normal pressure hydrocephalus: a single-center experience. World Neurosurg 83:387-393, 2015

39. Oliveira MF, Saad F, Reis RC, Rotta JM, Pinto FC: Programmable valve represents an efficient and safe tool in the treatment of idiopathic normal-pressure hydrocephalus patients. Arq Neuropsiquiatr 71:229-236, 2013

40. Paidakakos N, Borgarello S, Naddeo M: Indications for endoscopic third ventriculostomy in normal pressure hydrocephalus. Acta Neurochir Suppl 113:123-127, 2012

41. Petersen J, Hellström P, Wikkelsø C, Lundgren-Nilsson A: Improvement in social function and health-related quality of life after shunt surgery for idiopathic normal-pressure hydrocephalus. J Neurosurg 121:776-784, 2014

42. Pinto FC, Saad F, Oliveira MF, Pereira RM, Miranda FL, Tornai JB, et al: Role of endoscopic third ventriculostomy and ventriculoperitoneal shunt in idiopathic normal pressure hydrocephalus: preliminary results of a randomized clinical trial. Neurosurgery 72:845-854, 2013

43. Pujari S, Kharkar S, Metellus P, Shuck J, Williams MA, Rigamonti D: Normal pressure hydrocephalus: long-term outcome after shunt surgery. J Neurol Neurosurg Psychiatry 79:1282-1286, 2008

44. Raftopoulos C, Massager N, Balériaux D, Deleval J, Clarysse S, Brotchi J: Prospective analysis by computed tomography and long-term outcome of 23 adult patients with chronic idiopathic hydrocephalus. Neurosurgery 38:51-59, 1996

45. Rangel-Castilla L, Barber S, Zhang YJ: The role of endoscopic third ventriculostomy in the treatment of communicating hydrocephalus. World Neurosurg 77:555-560, 2012

46. Relkin N, Marmarou A, Klinge P, Bergsneider M, Black PM: Diagnosing idiopathic normal-pressure hydrocephalus. Neurosurgery 57 (3 Suppl):S4-S16, ii-v, 2005

47. Sankey EW, Jusué-Torres I, Elder BD, Goodwin CR, Batra S, Hoffberger J, et al: Functional gait outcomes for idiopathic normal pressure hydrocephalus after primary endoscopic third ventriculostomy. J Clin Neurosci 22:1303-1308, 2015

48. Shaw R, Mahant N, Jacobson E, Owler B: A review of clinical outcomes for gait and other variables in the surgical treatment of idiopathic normal pressure hydrocephalus. Mov Disord Clin Pract (Hoboken) 3:331-341, 2016

49. Sheth SA, McGirt M, Woodworth G, Wang P, Rigamonti D: Ultrasound guidance for distal insertion of ventriculo-atrial shunt catheters: technical note. Neurol Res 31:280-282, 2009

50. Spagnoli D, Innocenti L, Bello L, Pluderi M, Bacigaluppi S, Tomei G, et al: Impact of cerebrovascular disease on the surgical treatment of idiopathic normal pressure hydrocephalus. Neurosurgery 59:545-552, 2006

51. Stranjalis G, Kalamatianos T, Koutsarnakis C, Loufardaki M, Stavrinou L, Sakas DE: Twelve-year hospital outcomes in patients with idiopathic hydrocephalus. Acta Neurochir Suppl 113:115-117, 2012

52. Suchorska B, Kunz M, Schniepp R, Jahn K, Goetz C, Tonn $\mathrm{JC}$, et al: Optimized surgical treatment for normal pressure hydrocephalus: comparison between gravitational and differential pressure valves. Acta Neurochir (Wien) 157:703-709, 2015 
53. Thomas G, McGirt MJ, Woodworth G, Heidler J, Rigamonti D, Hillis AE, et al: Baseline neuropsychological profile and cognitive response to cerebrospinal fluid shunting for idiopathic normal pressure hydrocephalus. Dement Geriatr Cogn Disord 20:163-168, 2005

54. Thompson SD, Shand Smith JD, Khan AA, Luoma AMV, Toma AK, Watkins LD: Shunting of the over 80s in normal pressure hydrocephalus. Acta Neurochir (Wien) 159:987994, 2017

55. Toma AK, Papadopoulos MC, Stapleton S, Kitchen ND, Watkins LD: Systematic review of the outcome of shunt surgery in idiopathic normal-pressure hydrocephalus. Acta Neurochir (Wien) 155:1977-1980, 2013

56. Tschan CA, Antes S, Huthmann A, Vulcu S, Oertel J, Wagner W: Overcoming CSF overdrainage with the adjustable gravitational valve proSA. Acta Neurochir (Wien) 156:767-776, 2014

57. Tullberg M, Persson J, Petersen J, Hellstrom P, Wikkelso C, Lundgren-Nilsson A: Shunt surgery in idiopathic normal pressure hydrocephalus is cost-effective-a cost utility analysis. Acta Neurochir (Wien) 160:509-518, 2018

58. Virhammar J, Laurell K, Cesarini KG, Larsson EM: Preoperative prognostic value of MRI findings in 108 patients with idiopathic normal pressure hydrocephalus. AJNR Am J Neuroradiol 35:2311-2318, 2014

\section{Disclosures}

Dr. Lanzino reports a consultant relationship with Medtronic.

\section{Author Contributions}

Conception and design: Lanzino, Palandri, Elder. Acquisition of data: Giordan. Analysis and interpretation of data: Giordan, Palandri. Drafting the article: Giordan, Palandri, Elder. Critically revising the article: Lanzino, Giordan, Palandri, Murad. Reviewed submitted version of manuscript: all authors. Approved the final version of the manuscript on behalf of all authors: Lanzino. Statistical analysis: Giordan, Murad. Study supervision: Lanzino, Giordan.

\section{Correspondence}

Giuseppe Lanzino: Mayo Clinic, Rochester, MN. lanzino. giuseppe@mayo.edu. 